\title{
The Logic of Normative Justification
}

\author{
Gregory Carneiro ${ }^{1}$
}

'University of Brasília, Department of Philosophy, Brasília-Brazil

ORCID: G.C. 0000-0001-9059-4372

\section{Sorumlu yazar/Corresponding author:}

Gregory Carneiro,

University of Brasília, Department of

Philosophy, Brasília-Brazil

E-mail/E-posta: gregorycarneiro@outlook.com

Başvuru/Submitted: 28.10.2019

Kabul/Accepted: 03.01.2019

\section{Atıf/Citation:}

Carneiro, Gregory. (2019). "The Logic of Normative Justification" Felsefe Arkivi- Archives of Philosophy, 51: 79-115.

https://doi.org/10.26650/arcp2019-5106

\begin{abstract}
What really makes the concepts of obligation or permission so important for practical philosophy? What if we could find a better concept, one that, despite the simplicity, could show itself as intuitive and rich as possible? Could justifications be used in common language and practice as a sign of ethical judgment and as a strong motive for action? In most scenarios, for example, it really doesn't matter if a given action is obliged, permitted or forbidden, one may perform the action as long as a justification for doing it is present. In this sense, the notion of justification seems to be more basic and powerful than other concepts used in the philosophical discourse. The existence of formal systems based on the epistemological side of justification, created by Artemov, led us primarily to think that justification could make the formal discourse much more accurate for ethics than the ones using deontological concepts. In the semantical and syntactical aspects, almost all of Artemov's systems directly proved to be fruitful for ethical purposes. We also developed combinations between the standard deontic logic and logics of justification, resulting in what whe called the Logics of Normative Justification. These systems were able to change the object of the justification formulas and shed some light in ethics as a whole, normative and metaethics. Metaethics were a forgotten subject in formal ethics. We were also able to deal with some known problems in deontic logic, like the famous Ross's paradox and the expressiveness of prima facie and all-things-considered obligations.
\end{abstract}

Keywords: Deontic logic, modality, justification, ethics, metaethics 


\section{Introduction}

${ }^{1}$ It is disappointing to the logical community, scholar of ethics or to anyone immersed in the universe of practical philosophy, that we do not have an effective formal system capable of serving for conceptual analysis of ethics. The formal normative systems that have emerged to this day may have some use for a lawyer, computer scientist, and with much effort some occasional contributions on the normativity of ordinary human actions. It is possible, for example, that we have a logic of ethics about the traffic, correct behavior during a dinner party or the correct way to communicate with elderly people. It is not difficult to imagine a logic that deals with these more restricted spaces. The problem might be that those possible particular systems, although having behavior, ethical aspects and logic, miss what makes formalizations interesting for philosophy: the ability to separate the important from the superfluous aspects of the issues addressed, considering the universe as a whole. Cutting the universe of ethics in little segments to facilitate a logical application is to underestimate philosophical demands and to undermine the developments conquered with much effort by logics in the history of philosophy.

An important aspect of ethics, which is overlooked in famous studies known and often quoted, and which raises crucial philosophical questions, is metaethics. Metaethics state questions of this sort: is there such a thing as goodness? Why should I stop doing something evil? Is it obligatory to do good actions? Is there such a thing as bad actions? What is its nature? What predicates should an action have in order to be considered good? What about a malicious action, does it have any unshakable predicate? They are common philosophical questions that appear in ancient philosophy, problematic since then, whose discussion has never been approached by logicians. The fact that, to this day, nobody has tried to formalize metaethics is a very good motivation for the enterprise. After all, formal systems suited to dealing with metaphysical and epistemological issues did not exist until the publication of pioneering works. So, it is necessary the audacity to face a complicated subject without established studies and, of course, to have the ability to criticize the status quo of normative logic, that until now appears to have forgotten a relevant part of ethics.

\section{Contemporaneous Normative Logic and Ethics}

Normative logic has been dominated by an endless discussion about deontology, which is, in short, the study of deontic objects, like obligations and permissions, formalized or not. Formally, the deontic logic idealized by Georg Von Wright (1951) is very simple, and at the same time it is, to this day, considered by many deserving of the name Standard Deontic Logic (SDL). SDL is nothing more than an extension of classical logic, usually with the primitive modal operator for obligation "O", with " $\mathrm{P}$ ” and " F", for permission and prohibition, defined.

Following an adapted version of Paul Mcnamara’s presentation (2014), beginning with its alphabet and formation rules, we have:

1 This article is based on a master's degree dissertation, fully developed at the University of Brasilia Philosophy Department, by the years of 2018 and 2019, founded by the Brazilian Council for Scientific and Technological Development (CNPq). 
(i.) Propositional variables: $p, q, r \ldots p_{1}, q_{1}, r_{1} \ldots, p_{2}, q_{2} . ., p_{3} \ldots{ }^{2}$;

(ii.) Propositional constants: $\perp, \mathrm{T}$;

(iii.) Operators: $\neg, \wedge, \mathrm{V}, \rightarrow$, and $O$;

(iv.) Parentheses: (,).

R1. Every variable and propositional constant is formula;

$\mathrm{R} 2$. If $A$ is formula, then $\neg A$ is also formula.

R3. If $A$ is formula and $B$ is formula, then $(A \wedge B),(A \vee B),(A \rightarrow B), O A$ are formulas.

Definitions:

D1. $P A:=\neg O \neg A$

D2. $F A:=O \neg A$

SDL holds the following axioms and inference rules:

A1. All axioms and rules of classic propositional logic;

A2. $O(A \rightarrow B) \rightarrow(O A \rightarrow O B) \quad$ K-deontic

A3. $O A \rightarrow \neg O \neg A \quad$ Deontic Consistency or D-deontic

R2. $\frac{\vdash A}{O A} \quad$ Deontic-Necessitation or NEC-O

$\mathrm{SDL}$ is a normal modal system $\mathrm{KD}$, therefore, it has all metalogical properties we need. In particular, SDL is satisfied by a structure $\left\langle W, R_{\mathrm{d}}\right\rangle$ such that $W$ is a non-empty set of alternatives $w$ (or possible worlds) and $R$ is a binary relation between the alternatives with the condition of seriality - for each alternative $w$ there is another subsequent alternative $w^{\prime}$ and there is an accessibility relation between the worlds $w$ and $w^{\prime}$.

Although several philosophical readings may be given for what an alternative is, the most common is to consider alternatives as configurations of the world that are normatively closer to perfection. Adding a valuation $\vartheta$ to the structure $\left\langle W, R_{\mathrm{d}}\right\rangle$, we get a Kripke's model for SDL. Considering that $A T O M$ are the propositional variables of the SDL language, $\left\langle W, R_{\mathrm{d}}, \vartheta\right\rangle, \vartheta=$ $A T O M \times W \longmapsto\{\mathrm{T}, \mathrm{F}\}$ is a function of the relation between atomic and deontic alternatives $(\mathrm{W})$ in $\mathrm{T}$, F, in which $\vartheta(A, w)=T$ or simply $w=A$. Considering the model, we can immediately define the notion of satisfiability in for $\mathrm{SDL}^{3}$.

2 Uppercase latin letters $\mathrm{A}, \mathrm{B}, \ldots A_{1}, B_{1}, \ldots A_{\mathrm{n}}, B_{\mathrm{n}} \ldots$ will be metavariables.

3 Aside the boolean operators, that is satisfied as usual, the condition the SDL's characteristic formulas "obligatory that..." is presented like this: $W \vDash O A$ iff for every $w^{\prime}$ such that $w R_{d} W^{\prime}, W^{\prime} \vDash A$. 
Note that the seriality condition of $R$ is required for SDL models, since the world that does not access any other world, often called the terminal world, cannot be a model for SDL.

Following in the footsteps of Carnielli and Pizzi (2008) and Blackburn, Rijke and Venema (2002), we could prove that all normal modal logics are satisfied by a class of Kripke's models ${ }^{4}$. SDL is a normal modal logic, since we have a deontic reading of $K$, dual as the definition $D 1$ and O-NEC. Considering that, it is easy to show the soundness $(\vdash \Rightarrow \Vdash)$, that the axioms and rules of SDL preserve validity for a class of Kripke's models. The challenging part of the proof is to show completeness. Nonetheless, the strategy for this is standard: first, we construct a canonical model; and then we prove that serial models are particular cases of the canonical models.

If our analysis of SDL were supposed to stop at this point and we wanted nothing more than one random connection between a set of actions and "possible" worlds (also called deontic alternatives), the conclusion would be that the deontic logic deserves to be called standard. What, then, justifies investigating a different deontic system? The answer to this question would require a presentation of the known problems of SDL, but SDL's limitations are today more standard in the literature than the very logic that contains them. It would be uninformative and perhaps tedious ${ }^{5}$. Instead, we should jump directly to the philosophical part.

\subsection{Jørgensen's dilemma and justifications}

Jørgensen's dilemma (1937) seems to be most interesting of the SDL's problems, because it is a central debate in any normative logic, not only SDL. This dilemma is based on one simple fact: commands, in any linguistic variation, are not truth value holders. For example, "obligatory to stop the vehicle at red light" is the type of phrase that has no assertoric force, to use the more traditional vocabulary (Hare, 1996). It is not confirmed by events in the world, not even when someone indeed follows the rule. The contrast is evident when we assert that "people stop their vehicles at the red light" does have truth value, for being in the indicative mode. This distinction is easily noticed just appealing to common sense. Now, if a sentence does not have truth value, how could the logic of it exist? Logic is defined here as a formal system constituted by a syntax, holding an appropriate semantics and natural logical concepts, such as inference and valid argument. Let us take the concept of valid argument, a concept of indisputable application in philosophy and logic. A valid argument is, roughly speaking, an argument in which the truth of the premises guarantee the truth of the conclusion; or, in other words, in which it does not happen that the premises are true and the conclusion false. How would we be able to define a valid argument in a system whose linguistic elements, object of formalization, and consequently the premises and conclusions, do not even carry truth value?

4 A normal modal logic is, basically, any extension of the modal logic $K$, with dual and necessity. The are many equivalent forms to characterize normal modal logics. Carnielli and Pizzi (2008) use the scheme $G^{k, l, m, n}=\diamond^{k} \square^{l} \varphi \rightarrow$ $\square^{m} \diamond^{n} \varphi$. With this scheme it is possible to define normal modal logic as the whole extension of $K$ with an instance of $G$. For example, SDL is simply $K+G^{0,1,1,0}$.

5 For a broad view of the various paradoxes, puzzles and SDL's dilemmas, see (Mcnamara, 2018). 
Georg von Wright (1951) suggests that the simple act of transforming norms into propositions could avoid the dilemma, as follows: "It is obligatory to stop the vehicle in the red light". This form actually can be said to be true or false. Despite the suggestion, Jørgensen's dilemma still remains as a philosophical crossroad that constantly challenges the full development of deontic logic as an effectively formal discipline. Something like an irritating question that repeats itself permanently: where does the truth fit into these propositions? SDL, as we have seen, is a system that ignores the problem of truth in the normative realm.

The situation becomes even more complicated when we find that deontic logicians have been less and less creative when it comes to formal alternatives for SDL. If the problem is fundamental, as David Makinson (1999) suggests, on the basis of any normative reasoning, it will not be with purely linguistic maneuvers, such as transforming normative statements into propositions, or even assigning truth to rules ad hoc, that we will be able to see deontic logic free from the skepticism created by Jørgensen's dilemma. It is necessary to seek a specific philosophical concept of normativity, in principle one not so far from the normative world, which leaves no doubt that it applies to norms. In this sense, we will see how philosophy allows us to speak in normative justification to construct a better and more complete concept of normativity. It is important to note that the problem imposed by Jørgensen should not imply the denial of the existence of a connection between norms and truth. It is not necessary to make such a conjecture. The problem is, however, that truth cannot make a direct connection with our common normative intuitions and, of course, when embedded in a logic, it defies an enormous logical tradition. The way out of a philosophical problem always begins with the philosophy, not with purely formal tools. Where to find an original and useful output to Jørgensen's problem? As a sort of traditional basis for normativity throughout the history of Western philosophy, ethics emerges as the best place to think about the possible interactions between normativity and truth.

Adolfo Sánchez Vázquez (2013) helps us to take the first steps using ethics to clarify an important confusion that seems to be inside of all contemporary logics. In everyday life, of course, we act all the time. If we are thirsty and hungry at the same time, the decision to eat and drink water, or drink first and eat later, are practical decisions with no deep philosophical implications nor relevance to ethics. Ethics, as a theory of morally acting is, first of all, a theory. As such, one wants to know about the explanation of a type of human experience or form of behavior of men while considering in its totality, diversity and variety. (Vázquez 2013, 21). It is not, therefore, a simple description of mental states or an imposition of the environment, a topic to be confused with a branch of psychology or anthropology, but an explanation of human behavior in the sight of universal concepts. It is to be wondered even if deontology, that is now almost imposed as a ground for any formal normative discourse, is one of those concepts that are proper and central to any philosophical theory that approaches human agency.

There is no doubt that deontology is already present in most formal systems. In particular, it is present in the modal operators of $\operatorname{SDL}(O, P$ and $F)$. Its results, however, are notoriously unsatisfactory. In fact, all deontic logics known appear to be missing a concept. 


\section{Conceptual introduction to the Logic of Normative Justification}

In order to find some concept that supports deontology in the development of a new logic approach for ethics, we must first understand what is ethics, its main theories, and to what extent propositional deontic logic can be considered insufficient for philosophy.

Before we begin, two warnings: first, the terms "ethics" and "morals" will be treated as synonyms. Although there are authors that consider these terms in a different way, based on etymological premises, it has no relevance for our approach. Second, the "meta" prefix applied when we speak of metaethics has a much broader sense than when we speak of other metalinguistic discourses, especially the metalogical one. While metalogics is the analysis of logic by logic, metaethics is the analysis of ethics in its various basic aspects, as ontological, epistemological, logical and so on. They are two distinct "goals", and coincide only in what concerns this second order aspect.

For most, it is not clear what makes metaethics so important. In contemporary ethical theory (Copp 2006), this particular distinction between normative ethics and metaethics is common and fruitful. For example, when you see someone's wallet falling from his pocket in the middle of the street, we ask ourselves "is it okay to keep this lost wallet?" or "am i obliged to return this to the person who lost it?". The answer to these questions will ultimately determine whether you will return the wallet to the person who lost it or whether you will keep what you know does not belong to you. This is a trivial question, but at the same time reveals how ethics is something that influences the outcome of the simplest human actions - with a clear practical aspect. Clearly, not all human actions have the same degree of ethical relevance. If I go to the kitchen to drink water and decide to eat an apple as well, this does not have any immediate ethical repercussions. Turning off the medical equipment of a person in a coma, however, involves a series of analysis that goes beyond the mere "make-it-true" of human agency. In the case of euthanasia, it is important to think about what actually justifies the act of disconnecting the devices that keep a person alive, if we are allowed to affect the life of another human being who is unable to give his opinion about his own life, if life has a correct or worthy way of being lived, if to live it involves certain primordial abilities for happiness or is only a biological movement of brain activity an so on. The position of the philosopher on any of these questions defines what is commonly called normative ethics or normative morality. In other words, normative ethics are based on statements that immediately determine the action or the judgment about the action of another person. Normative ethics takes account of topics that are often controversial, such as abortion, freedom of expression, the death penalty, torture and terrorism.

The peculiarities of metaethics change the question's level. Whether there are moral facts that can be attributed to truth or falsity, whether there are moral properties, or how strong is the influence of emotions on human actions, are not themes that involve moral positions directly, but positions on moral positions, that eventually would become (normative) ethics. Let us take the case of euthanasia mentioned before. A person convinced that it is correct to disconnect 
the medical devices of a person in a vegetative state can be questioned in many aspects: does something justify as good the action of terminating one's life? Is there a model for a life that is worth living? What are the criteria for a decent life? Is it possible to find a similar pattern for all human actions that we name ethical or good? If there is no objective criteria, what ethically demands the action of turning the medical devices off or leaving them on? These are questions that do not decide anything about euthanasia directly, but seeks to explain the justification of an action from the view of normative ethics. That is what we meant when said that we have a switch in the level of questions: ethics as first order, metaethics as second order (Copp 2006, 5).

In general, metaethics make questions (Chrisman, 2016):

- About the existence and nature of ethical facts and ethical properties;

- $\quad$ About knowledge and ethical disagreements;

- About the meaning and use of ethical language;

- About ethical thinking and reasoning involving actions.

It will not be necessary to make a description of all metaethical positions. It is enough to briefly present two, just to set what is at stake for the logician who desires to formalize ethics as a whole.

The first one, ethical nihilism, is a metaethical theory that denies the existence of moral facts. It does not simply deny that there is an absolute standard for judging the morality of actions, it also denies that there is a property that could make a moral action good or bad. The consequence is that moral judgments can only be seen as mistakes about facts. Related to this metaethical position, we have realism, that commits itself to the existence of moral facts and their properties. For the realist, there are moral facts and they are the ones that determine if we act correctly or not in a given situation. It is easy to see that nihilism is a strong form of antirealism. How to formalize that, since a modal discourse (like SDL) treats actions as something to be obligatory from the beginning? Or, how to say something about realism in SDL, since there is no fact (or truth) in that normal modal logic? This vocabulary is way beyond any contemporary normative logical approach.

In fact, all major metaethical theories bring elements that can be strange for a standard normative logician. A standard deontic logician would certainly be uncomfortable with our short introduction to metaethics, because, in metaethics, we are constantly connecting facts, truth, falsity, knowledge, beliefs and so on. As well as all known deontic logics, SDL tries to put together modalities and actions and nothing else, so a certain inexpressibility was expected. Even in their extensions, combinations of SDL and other logics, at most try to make the factual aspects stronger, such as adding temporal modalities, variables for agents, other modalities, among other logical resources ${ }^{6}$. It is also true that the attempts to reduce deontic modalities to other modalities

6 For a good representative of this task, the strongest we could find, see (Rönnedal 2015). 
(Anderson 1967), or even structural reduction to a first-order logic (Bealer 1982), did not look into the exact problems of expressibility to be useful for ethics. There is no concept that represents an enrichment of the notion of normativity in SDL. Thus, it is doubtful from the ethical point of view that we can represent a nihilistic, relativistic, realistic system, among others, when we have only the notion of obligatory, permissible, prohibited action and the usual connectives. How could we say that no action is ethically correct (expressing a nihilist idea)? The reason why this does not seem possible is that even in nihilism there is a notion of normativity - but not that one implicit in SDL. This will be clarified later. In any case, deontic logic, despite not having an unequivocal interpretation, makes direct commitments with modalization of actions, so best case scenario it is only fit to deal with ethical discourse of the "first order".

The logical alternative to be presented must be developed with an heuristic reanalysis of its normative grounds, capable of providing a stronger idea of normativity. Our idea is to "reveal" some connections between actions and justifications.

\subsection{Ethical theories via justification}

It does not take many arguments to demonstrate that morality is a relevant part of philosophy. Since Aristotle, we have known that to talk about ethics is to talk about human action. Many approaches have been given to the ethical debate, many classifications have been presented, new names, which end up making the understanding difficult, more often without any corresponding philosophical contribution. Philosophers such as Hare (1996) are interested in the meaning of moral terms, other philosophers only in investigating whether there are moral facts or not. Some seek a psychological explanation for ethical positions, others based on epistemological features. We have seen that the level of distinction is based on propositions that aim to affect actions, and others, on a superior level, that aim to take care of the status of propositions about actions - ethics and metaethics, respectively. As much as we have realized that philosophers have contributed giving a good conceptual apparatus for ethical discourse, it is hard to see how we could go any further towards the development of good formal ethical tools without anything new in our ethical vocabulary.

Something that has not been exposed so far is the almost hidden use of the word "justification" for the characterization of many metaethical theories. We have known that justification plays an important role in epistemological modalities, since Plato. The open meaning of the term justification, however, suggests that its application is not restricted to epistemology. In fact, it applies to other fields of thought which have certain relations with modal reason. Metaethical theory immediately confirms that justification and ethics are naturally linked. Let us make this idea more evident.

In Moral Skepticism, Walter Sinnott-Armstrong (2015) characterizes moral nihilism literally in epistemological and doxastic terms: 


\title{
Dogmatic skepticism about moral knowledge is the thesis that no one knows if any moral belief is true; \\ Dogmatic skepticism about justified moral belief is the thesis that no one is justified in having any moral belief;
}

The element of belief, knowledge and justification show the epistemological meaning which we talked about in the introduction to metaethics.

From the point of view of realism, the corresponding ethical moral theory may have several "justificational" definitions. Of course, all of them referring to a moral fact and property. Remission is also obvious for one simple reason: if moral propositions have a truth value, then their definitions respect the same patterns of common propositions (as those of the natural sciences, for example). Therefore, in the same way they can be justified. Nothing prevents realism, such as the definition of knowledge as true and justified belief, and from the presented definition of moral skepticism, to be defined as follows:

\section{Moral realism is the metaethical position that states that all true moral propositions are justified by the existence of moral facts.}

Definitions using justification apply in a natural way to the metaethical theories, as we can see. Within ethical theories, this application is similar. Let us take, for a good example, a very famous definition in Kantian ethics (Kant 1995, 45):

\begin{abstract}
All imperatives oblige, whether hypotheticaly or categoricaly. The hypothetical represents the practical need for a possible action as a means to achieve anything else one wants (what one might want). The categorical imperative would be what represents us an action as objectively necessary by itself, unrelated to any other end.
\end{abstract}

And Kant continues:

In case the action is only good as a means to anything else, the imperative is hypothetical; if the action is represented as good in itself, therefore as necessary in a will in itself conforming to reason as the principle of that will, then the principle is categorical.

There is no doubt that the important Kantian ethics revolves around the the categorical imperative as universal law of rational action. Thus, if a theory is capable of translating this concept, it is able to deal with Kantian ethics (at least in the most relevant part). In the scope of a justificational view which we intended to give to ethics, the concept of a categorical imperative could be given in two ways:

Good action is the one that is its own ethical justification.

Good action is the one whose goodness in itself is justified. 
In Kantian philosophy, the normative content of an action is all transferred to the concept of justification. On the normativity of Kantian imperatives, Stephen Darwall (Darwall 2006, 285) says:

\begin{abstract}
Consider the judgment that it is wrong intentionally to mislead potential investors by hiding losses. Normativity says that if this is wrong, then there is a genuinely normative reason for corporate officers not to engage in this deception. But what is meant by such a "normative reason"? "Reason for acting" can mean three different things. A normative reason for acting is something that counts in favor of or justifies an action in deliberation about what to do.
\end{abstract}

The presence of justification could not be stated better. Nonetheless, it may be the case that the exposition has led to some very fair questions. Was not our work, until this point, abusing the semantic openness of the concept of justification? After all, we are really justified in our beliefs, as it is common to address. We have mathematical proofs, we have empirical evidence, we have testimonies that "justify" or not our epistemic position. At the same time, we have personal feelings, theories, codes, and community feelings that "justify" our way of acting with others, in society. In all cases, although very distinctive, we apply the same word: justification. The way the term applies to different cases does not appear to us as a problem, but more as philosophical potential of the concept of justification, that happens to be explored only in its epistemic version. We show that, in a very natural way, justification interacts with ethical and metaethical theories. There are no complications in those uses. Actually, we made the "translations" with a good measure of simplicity and without significant losses in the definitions. In some sense, as it is the case with Kant's definition of normativity, justification makes ethical theories more understandable. Moreover, it suggests a connection between ethics and epistemology that goes unnoticed in many expositions and has been ignored by the logicians ${ }^{7}$.

Jonathan Dancy $(2006,138)$ shows that when we look at the complexity of the normative phenomenon we come almost directly to epistemological reflections. In his words:

\title{
Some normative facts (...) are more complex than the simple fact that one is obliged to do it; They contain this [deontological] fact, but it also contains what makes this fact the case. (...) It is these metaphors that I think are the center of normative facts, by reference to which the normativity of all other [facts] must be understood.
}

7 One philosopher stands out in predicting the connection between epistemology and ethics, but in the opposite direction of what we have introduced. Roderick Chisholm $(1969,29)$ suggests that, "by introducing appropriate qualifications, we could formulate an ethical definition of "knowledge" that is not subject to difficulties. But no one has yet been able to formulate satisfactorily which predicates are necessary for this definition.". His attempt, which he claims to be frustrated, was to provide a definition of knowledge that was not circular, as if to know the truth of a proposition could implicate in the duty of an agent in believing the proposition. Some difficulties arise from the very indeterminacy of what it is to have a right or duty of action. The project follows and the author only conjectures that it lacks "qualifications" capable of showing the relation between ethics and knowledge. Comparing it with our discussion about justification, it is curious that Chisholm has conjectured this interaction, even though his focus was on knowledge, not on ethics. 


\begin{abstract}
Each given fact is the fact that another fact is in normative relation with an action (or belief, feeling or desire ...). This view holds that notions of reasons or duties are the center of normative notions. Valuable notions are normative as well, but they differ structurally from the deontic in terms of which normativity is characterized. What other notions are called normative? A common thesis is that the notion of belief is normative; Robert Brandom says that his version of belief is "normative all the way down".
\end{abstract}

Using "facts" and "reasons", Dancy concludes that normativity should say much more than deontic operators can logically express. For ethics there are data that are as important for the analysis of normativity as the exterior of deontic modalities, just as there is something else (justification) in epistemic modalities, as demonstrated in the works of Artemov. We do not aim to prove, as the Robert Brandom conjecture in Dancy's quotation, that belief is something normative, but to use justifications inside ethics as motivation for the logic of normative justification and show that: (1) normativity is not only deontology, as many deontic logician seems to think; (2) justification is a philosophically (and logically) term compatible with deontic operators.

Belief and justification together characterize a notion of knowledge, which is philosophically useful and ordered by the logics of Artemov. And since we show that there is equally strong evidence that points justification as something natural in ethics and metaethics as well, we could use the success of justification to develop a normative logic in the general sense (not just for the law or a specific ethical theory). It would not be a mistake to suppose that the arguments presented above motivate us to make an adequate exposition of the logics of justification (Artemov 2008), which will be the basis for the Logics of Normative Justification.

\title{
3. Artemov's Logics of Justification
}

There are many possible relations between epistemic logic and deontic logic. First, both are commonly taken as normal modal logics. Second, both had initial formulations that were problematic, especially for the emergence of counterintuitive results in relation to the philosophy of knowledge. In particular, the modal epistemic logics that emerged in the second half of the twentieth century used modal operators for knowledge and belief. Taking knowledge as a primitive operator and without interdefinition between the concepts of knowledge and belief, the early epistemic logic did not use the definition of knowledge from the works of Plato, especially in the Theaetetus. For many logicians, this was the origin of many logical problems in epistemic logic (see Gettier 1963).

The logics of justification, therefore, were developed primarily with the purpose of treating epistemological problems and providing an approach that the traditional philosophy already strongly suggested. The simplicity of the syntax, semantics, and immediate metalogical results are impressive, as we will see in the presentation (adapted in a few points) that follows from the article The Logic of Justification (Artemov 2008). 
In brief, the Logics of Justification are a family of logics constructed above a classic propositional logic, enriched with justificational propositions of the type

$t: A$

which we can read as " $t$ is a justification for $A$ ". In order for us to really understand the proposed enrichment, we need to make the logic of justification from the beginning.

The syntax of the logic of justification has the following alphabet:

(i) Propositional variables: $p, q, r \ldots p_{1}, q_{1}, r_{1}, \ldots, p_{2}, q_{2}, \ldots, p_{3}, \ldots .8$.

(ii) Propositional Constants: $\perp, T$;

(iii) Justificational terms $(\mathrm{t})$ :

$$
t=\left\{\begin{array}{l}
\text { Justificational variables: } j_{1} j_{1}, j_{2}, j_{3}, \ldots, j_{n} \\
\text { Justificational constants: } j^{*}, j_{1}^{*}, j_{2}^{*}, j_{3}^{*}, \ldots, j_{n}^{*}
\end{array}\right.
$$

(iv) Operators: $\neg, \wedge, \vee, \rightarrow, .,+, !, ?$;

(v) Parentheses: (,).

R1. Every propositional variable and constant is formula;

R2. If $A$ is formula, then $\neg A$ is also formula.

R3. $j$ and $j^{*}$ are justificacional terms;

R4. If $t$ and $t^{\prime}$ are justificational terms, then $\left(t . t^{\prime}\right),\left(t+t^{\prime}\right),(! t)$ and $(? t)$ are justificational terms ${ }^{9}$;

R5. If $A$ and $B$ are formulas $t$ is a justificational term, then $(A \wedge B),(A \vee B),(A \rightarrow B)$

$(A \rightarrow B)$ and $(t: A)$ are formulas ${ }^{10}$.

8 As we did for SDL, let us consider uppercase latin letters $\mathrm{A}, \mathrm{B}, \ldots, A_{1}, B_{1}, \ldots, A_{n}, B_{n} \ldots$ as propositional metavariables.

9 Just to avoid loading the notation with numeric subscripts, we are going to use lines in the justificational terms $\left(t^{\prime}, t^{\prime \prime}, t^{\prime \prime \prime}, \ldots\right)$ to say, within a same context, that we are talking about different terms. As it designates the term $t$, whenever used in some formula, it can be a justificational constant and variable, or a complex term that arises from an operation among other less complex terms.

10 Note that $A$ can be a justificational formula $t: B$, for example. In this case, we know that $\left(t^{\prime}+t^{\prime \prime}\right):(t: B)$ is also a formula, since $t: B$ is a formula and $\left(t^{\prime}+t^{\prime \prime}\right)$ is a complex justificational term. 
The axioms that characterize its various systems are:

1. $\quad t:(A \rightarrow B) \rightarrow\left(t^{\prime}: A \rightarrow\left(t . t^{\prime}\right): B\right)$

Application (AA)

2. $\quad t: A \rightarrow\left(t+t^{\prime}\right): A$

Monotonicity (MON)

3. $t: A \rightarrow A$

Factivity (T)

4. $t: A \rightarrow ! t:(t: A)$

Positive introspection (PI)

5. ᄀt: $A \rightarrow$ ?t: $(\neg t: A)$

Negative introspection (NI)

6. $\neg t: \perp$

Consistency $(\mathrm{CA})^{11}$

And the internalization rule (IR):

For every axiom A and some justificational constant $j^{*}$, we infer $j^{*}: A$

The application axiom is the justificational version of axiom $\mathrm{K}$ from the usual epistemic logic. The difference is that applying the justification $t$ in $A \rightarrow B$ and $t^{\prime}$ with $B$ implies a more complex justification ("applied"), which is $\left(t . t^{\prime}\right): B$. This is an important distinction to be made, since the epistemic version $K(A \rightarrow B) \rightarrow(K A \rightarrow K B)$ results in problems of logical omniscience $^{12}$. The monotonicity axiom takes intuition from a logic of proofs. If a theorem $A$ has a proof, and another proof $t^{\prime}$ is developed, we know that $t+t^{\prime}$ remains a justification (in this case, represented by a formal proof) for A. Similar to the application axiom, the factivity axiom has a direct parallel with the epistemic modal $\mathrm{T}$ axiom $K A \rightarrow A$. Just as the knowledge of a proposition implies the truth of the proposition, the proposition having a justification implies its truth. A very strong statement, because it cannot be said, in general, that all justification entails truth, which leads the factivity axiom to be out of many systems of justification, as we shall see in the next section.

The introspection axioms, positive and negative, are related to the modal axiom $K A \rightarrow K K A$, which intuitively says that if we know something, we know that we know something. In the field of justification, something similar happens, which Artemov calls "proofchecker" in the logic of justification. If the proposition $A$ has a justification, then we have a way of checking (!) if this is in fact a justification. Likewise, if any $t$ is not a justification for $A$, the axiom states that we would have a way of checking (?) that $t$ is not a justification for $A$.

11 Artemov does not even give a name for this axiom. Roman Kuznets (2008) calls it the consistency axiom. Let us follow this suggestion to facilitate communication from now on.

12 The problem derives from the consequence of epistemic closure - which is the property of an epistemic agent, that is known as a given set of propositions, then any propositions that are a logical consequence of this set will also be known by the agent (Branquinho, Murcho and Gomes, 2006). This is naturally problematic. In order to visualize, logic itself is a good example: knowing the axioms of a logic is feasible, but it does not imply that all the theorems of this logic are known. In fact, it is common to know the former, given the finitude of simpler systems, but not know the latter, since it is potentially infinite. 
The last axiom simply states that there is no justification for falsum $(\perp)$. Since all Artemov's systems are classical in its basis, it is equivalent to say that contradictions are not justified. It is a position that demands certain reflections, since philosophy today accepts contradictions as a "natural" part of the world, and not only of theories (Priest, 2006).

The internalization rule (IR) is nothing more than a refined version, as we shall see, of the modal"necessitation" in the logic of justification. For systems with appropriate CS (constants specification), it is guaranteed that we have a set of formulas $j^{*}: A \in C S$, for all axioms A. In the conventional necessitation of epistemic logic $(\mathrm{K})$, all axioms are "known", including the axioms that contain the operators $\mathrm{K}$. It is an aspect of what we have called logical omniscience ${ }^{13}$.

Considering that all Artemov's systems are extensions of classical propositional logic, different combinations of the axioms form different systems with their own characteristics and applications in philosophical problems. Putting on a list:

1. $J_{0}=A A+M O N$

2. $J=A A+M O N+I R$

3. $J_{0} T=A A+M O N+T$

4. $J T=A A+M O N+T+I R$

5. $J 4=A A+M O N+I R+P I$

6. $J T 4=A A+M O N+I R+T+P I$

7. $J 45=A A+M O N+I R+P I+N I$

8. $J D 45=A A+M O N+I R+P I+N I+A C$

9. $J T 45=A A+M O N+I R+P I+N I+T$

The semantics for these logics of justification follow the pattern presented for modal logic. Only one peculiarity appears in the interpretation for justificational terms, as one should expect.

Let it be the structure

$D=\left\langle W, R_{j}, \varepsilon\right\rangle$ such that $W \neq \emptyset ; R_{j} \subseteq W \times w$; and $\varepsilon: t \times F O R \mapsto P(W)$.

13 In the original presentation of the logics of justification, if we have an axiom A and a justification $J_{1}^{*}$, then we have $J_{1}{ }^{*}: A$, where index 1 is an agent, and we want to postulate this justified as an axiom, then we have $J_{2}{ }^{*}:\left(J_{1}{ }^{*}: A\right)$ and so on. Hence there is no need for a generalized presentation for $J_{n}{ }^{*}$ for Artemov. Our purpose does not involve this generality, so it will be ignored hereafter. 
Where $W$ is a non-empty set of possible worlds $w$ (possible situations, for Artemov) $)^{14}$, where $R_{j}$ is the justificational accessibility relation. The least usual element added to the usual Kripke's structure, the admissible evidence function $\mathcal{E}$ designates a set of possible worlds in which $t$ is an admissible justification for $A$. In simple words, it is the set of worlds that admit some evidence as $\mathcal{E}(t, A) \subseteq W$. The relation $R_{j}$ and the admissible evidence functions have constraints for general satisfaction of the axioms of the logics of justification:

- $R_{j}$ can be euclidean ${ }^{15}$, serial, reflexive, transitive and monotonic in relation to $E$ :

If $w R w^{\prime}$ and $w \in \varepsilon(t, A)$, then $w^{\prime} \in \mathcal{E}(t, A)$.

- $\mathcal{E}$ is specifically under the following conditions:

Application: $\mathcal{E}(t, A \rightarrow B) \cap \mathcal{E}\left(t^{\prime}, A\right) \subseteq \mathcal{E}\left(t . t^{\prime}, B\right)$;

Sum: $\varepsilon(t, A) \cup \mathcal{E}\left(t^{\prime}, A\right) \subseteq \varepsilon\left(t+t^{\prime}, B\right)$;

Positive introspection: $\mathcal{E}(t, A) \subseteq \mathcal{E}(! j, t: A)$;

Negative introspection: $(\mathcal{E}(t, A))^{c} \subseteq \mathcal{E}(? j, \neg t: A)$;

Strong Evidence: for all $w$, such that $w \in \mathcal{E}(t, A)$, then $w \vDash t$ : $A$;

Stability: if $w R w^{\prime}$, then $w \in \mathcal{E}(t, A)$ iff $w^{\prime} \in \mathcal{E}(t, A)^{16}$.

All logic of justification respects the closure condition for CS, as follows:

If $j^{*}: A \in C S$, then A-axiom, then $\varepsilon\left(j^{*}, A\right)=W$.

In every W-worlds it maintains the justification constant as an admissible evidence for the axiom.

It is important to note that if $w \in \mathcal{E}\left(j^{*}, A\right)$ for any $j^{*}: A$, then $\mathcal{D}$ respects CS in $w$. For one of the systems we will use, JD45, CS is axiomatically appropriate, which guarantees IR, as we will see to be essential for the demonstration of completeness.

Immediately we can present a general model for the logics of justification:

$M=\langle\mathcal{D}, \vartheta\rangle$

14 Possible situations and words will be used as synonyms, since both carries its own philosophical intuition in ethical discourse.

15 which means that for all $w, w^{\prime}$ and $w^{\prime \prime}$, if $w R_{i} w^{\prime} w R_{j} W^{\prime \prime}$, then $w^{\prime} R_{i} W^{\prime \prime}$.

16 That is an independent condition that can be placed as a consequence of the monotonicity of $R$ in relation to $\varepsilon$. Due to an interesting "configuration", we choose to maintain explicitly, as was done in the original work by S.

Artemov. 
In this case, $\vartheta=A T O M \times W \longmapsto\{\mathrm{T}, \mathrm{F}\}$ is a function of the set of relations between atomic and possible situations (W) in T, F , where $\vartheta(A, w)=T$ or, in the usual abbreviation, $w \vDash A$, which is read as " $A$ is true in the possible world $w$ ". Considering the model, we can finally define the satisfaction relation for the logics of justification:

$\vartheta(p, w)=T$ or $\vartheta(p, w)=F, p$ is a atomic formula;

$w \vDash p$ iff $\vartheta(p, w)=T$ in $w \in W$, p-atomic;

$w \vDash t$ : $A$ iff for all $w^{1}$ such that $w R_{\jmath} w^{\prime}, w^{\prime} \vDash A$ and $w \in \mathcal{E}(t, A)^{17}$;

The role of the admissible evidence function is to give extra satisfiability conditions for $t: A$ within the model: it is true that $t: A$ in $w$ if, for every possible situation $w^{\prime}$, which is in relation $R_{J}$ with the situation $w, A$ is the case in $w^{\prime}$; but not only this, since $t$ has to be considered as admissible evidence for $A$ in $w$ (the current possible situation/world). The monotonicity of $R_{p}$ or the implied stability of $\mathcal{E}$, guarantees that the accessibility relation "transfers" also the admissibility of the evidence for other situations $w^{\prime}$. The presence of a justificational term in the logics of justification is not only a syntactic maneuver, but represents a true theoretical improvement.

In addition, all the systems presented in the previous section are correct and complete given $\mathcal{M}$ with the appropriate constraints for $R_{J}$ and $\mathcal{E}$.

Although Artemov presents a plurality of logics, only the two strongest systems (JD45 and JT45) will be used hereafter. JD45, in particular, has the interesting axiom of consistency, which may offer good readings for a normative logic, which traditionally has an axiom for consistency, either in its classical basis or its own deontic consistency (like in SDL). JT45 would be problematic in the intuitive sense because of the axiom of factivity. Normativity, also traditionally, rejects the principle of factivity. After all, the commands should never imply in a fact. This is the content of Hume's guillotine, which we shall deal with briefly later. However, this complete rejection of the principle of factivity seems to be embedded in a preconception of what an ethical phenomenon should be and how diverse can its theories be. Realism does not seem to reject this connection between norms and facts, since there are moral facts, which are the ultimate reference of morality.

The motivation and consequent explanation given by Artemov in any of his systems of justification always draws lessons from epistemology. There is no immediate debate on ethics in his writings. Thus, it is good that we take into consideration the type of challenge that is to speak of ethics with a system that is focused on another field of philosophy. The intuitive interpretations that will follow may suggest that we have ignored not only the implicit presence of justification in ethics but also the philosophical bridges between ethics and the great field of epistemology.

17 The satisfiability for boolean operators is defined as usual. 


\subsection{The Logics of Justification from a Normative Point of View}

Without being afraid to show some pessimism with the situation of logic applied to ethics, we can say that deontology completely dominated the reasoning that is called normative. And, if SDL is a representative of normativity in logic despite all its problems, seems correct to say that the use of deontology as foundations for normative reasoning has not been successful as expected for a formal system to be useful for the philosopher (Åqvist 1987, 10). The introductory explanation, with a special focus on metaethics, showed that, on one hand, not everything in ethics is deontology, the field of normative ethics, and, on the other hand, that metaethics is an important field of philosophy about human agency. Moreover, metaethical theories showed that, despite the plurality of existing approaches and varied responses, everything can be summed up in simple terms of justification of moral propositional attitudes.

So justification is the concept chosen for this attempt to extend the power of normative logic and a release of its limitations. And the suggestion that ethics is a field of justification is so natural, and carries such an intuitive appeal, that the very presentation of the basic axioms of Artemov's logic suggests an acceptable "normative" interpretation. Let us see how this works.

Just as in metaethical theory, it is common to see justification as a term used systematically in everyday discourse, although inadvertently most times. Especially in the face of an action judged by popular opinion, we frequently hear phrases that say "what is the justification for doing this?", "this action was unjustified!", "what they did to me is not just" or, if there is a tone of approval, "It's reasonable to do that". All sentences, in a certain way, indicate the idea that actions, as well as the object of knowledge, may or may not have justifications. We are interested in moral justifications as theories that approve a particular action or disapprove it. Thus, if according to a certain moral code, let's say a hedonistic one, to perform actions that lead to the greatest pleasure are justified, and if to eat ice-cream before dinner causes more pleasure to the agent than to do it differently, it can be affirmed that "the agent is justified in eating ice cream before dinner". In the same way, people who are obliged or permitted by any code to do $x$ are also justified prima facie, by the same code, to do $x$. The connections are pretty straightforward.

For a formal idea of this approach, consider $t: A$ as "the agent has (moral) justification $t$ to do $\mathrm{A}$ " or, more simply and hiding the agent, " $t$ is a (moral) justification for the action $\mathrm{A}$ "18. This new reading of $t$ and in the conversion of a propositional logic into a simple logic of actions completely changes the meaning of the axioms of Artemov. Let us take a look at the application axiom:

$$
t:(A \rightarrow B) \rightarrow\left(t^{\prime}: A \rightarrow\left(t . t^{\prime}\right): B\right)
$$

Following the suggested reading, the axiom is interpreted as follows:

If $t$ is a justification for an action $A$ that implies $B$, then if $t^{\prime}$ is justification for doing $A, t . t^{\prime}$ is a justification for doing $B$.

18 A similar approach was suggested independently by (Faroldi and Protopopescu 2019). 
It is interesting to note some details of the axiom, which make all sense from a moral point of view. If there is a justification $j$ to do a conditional action (e.g., if I am hungry (A), then eat something healthy (B), for thus I promised my parents $(t)$, in the case, because it is dinner time, there is a justification $t^{\prime}$ to be hungry, so the combination of the promise $t$ and the dinner time $t^{\prime}$ justifies the action of eating something healthy. Observe that the asymmetry imposed on the conditional is important to formalize the way we reason with actions. What justifies the implication is the promise made to the parents only, but hunger and eating something healthy have other justifications that set a different dynamic to the context. After all, nobody is ever hungry due to a simple promise, so this situation requires a different justification. In particular, action B, of eating something healthy, makes use of the two previous justifications, in an interesting way, as if it were not enough to keep the promises or be at dinner time, but needed both to perform the action of eating something healthy. It is good to remember that the interaction described here is about moral justifications (as far as possible) and how they act in a certain logical environment. It does not mean, and logic does not impose this type of limitation, that an agent cannot (metaphysically speaking) eat something unhealthy and not be hungry at dinner time, doing the opposite what was promised.

The monotonicity axiom performs as in its epistemic version. From a relativistic perspective, suppose that the action of helping the poor is a justified action in Christian morality $(t)$, and under the Hindu perspective helping the poor is a justified action $\left(t^{\prime}\right)$ as well, so the combination of the two justifications $\left(t+t^{\prime}\right)$ remains a justification for helping the poor. In its formalized version:

$$
t: A \rightarrow\left(t+t^{\prime}\right): A
$$

By symmetry with the modal axiom $\mathrm{T}$, the factivity axiom in the logic of justification also has its normative version hard to make sense. This is due to the fact that moral determinations, norms, do not usually imply truth. This is similar to the Jørgensen's dilemma, which was explained. There is a line between an ideal state of action, of what ought-to-be, and what really happens, of realm of being. This is what is often called the naturalistic problem, which Hume already warned us about in his Treatise (2009, 509):

In every moral system I have ever encountered, I have always noticed that the author follows for some time the common way of reasoning, establishing the existence of God, or making observations about human affairs, when, suddenly, I am surprised I can not find a single proposition that is not connected to another by a should or should not. This change is imperceptible, but of the utmost importance. For, as this should or should not express a new relation or statement, it would have to be noticed and explained; at the same time, it would be necessary to give a reason for something that seems entirely inconceivable, that is, how this new relation can be deduced from others entirely different.

This distance, however, does not exist from a realistic point of view. So, if the created ethics is based on a metaethical realistic view, on the existence of moral facts, being justified by $t$ in doing A implies the existence of the moral fact $\mathrm{A}$, in the logical sense. It is precisely what the factivity axiom says: 


\section{$t: A \rightarrow A$}

A logic of ethics with the facitivity like axioms, we conjecture, would hardly be able to move away from his philosophical commitment to moral realism.

It is worth remembering, also, that the approach now presented of the logics of Artemov appears as good logic for normative ethics, not metaethics. Although, as it might seem, metaethics has its share of influence in the normative ethics. They cannot be totally separated. In this subject, the axiom of introspection reflects in some extent this inevitable connection between normative and metaethical ethics:

$$
t: A \rightarrow ! t:(t: A)
$$

A theory or code is able to verify by some instrument whether the justification that the agent/action sustains is a genuine justification, for example, ratified by a theory/code. Helping the poor is a normatively-ethically-justified action, then, in some theory confirms that there is a strong theoretical framework, e.g., in Christian ethics as a divine commandment that says "God commanded to help the poor, then it is the right thing to do". From the ethical side, this is the same behavior that a proof has in the formal field, such as mathematics. A formal proof (human or computer-made) is not only verification as finite, logically correct steps towards an expected result, but is also an authorization for the use of the result in formal practice. Due to a proof, for instance, the mathematician is "justified" in the use of that mathematical truth. Likewise, metaethics authorizes the use of a certain ethical justifications for an action. The axiom, in other words, can show how ethics and metaethics interact in the treatment of practical philosophy.

The negative introspection axiom goes in a similar direction and complements the connection between ethics and metaethics. It occurs, however, if $t$ is not a justification for an action $A$, then there is a theory that confirms it is not. From the brief explanation of metaethical theories, it is shown that as important as what ethics says is correct to do is to say what is not right to do. That is somehow paradoxical, but immorality is what occupies the mind of moralists. It is important to observe that not all metaethical theories will "verify" justifications. A nihilist view rightly denies this axiom.

In order to respect the classical character of ethical logics, it is immediate that contradictory actions are not equally justified. That is why the logic of justifications carries the consistency axiom:

$$
\neg t: \perp
$$

Nonetheless, this axiom can hardly be placed for ethics that are instances of a relativistic way of looking at moral theories. Relativism has to be able to withstand a certain level of contradiction - once we admit as correct our justificational definition of relativism, that every action can be ethically justified. This particular axiom draws our attention to relativism, since the treatment of relativism within ethics resembles trivialization in logic. To show that an ethical theory is relativistic, or implies relativism, is to show that it is useless for ethics (in a broad sense). One has 
to wonder about the true force of this parallel and if it deserves attention. If yes, the above axiom makes direct reference to a negation of relativism in the normative interpretation of the logics of Artemov - contradictory actions cannot be both justified. Without the consistency, the axiom may put relativism closer to a dialetheism (Priest 2006) within metaethics - an opportunity to deal with normative justification of inconsistent actions.

The difference between justificational variables and constants, placed by the rule of internalization, can provide the distinction necessary for a competent representation of obligations and permissions only on the basis of justification. After all, whoever is obliged to do A is, at the same time and under the same aspect of the agency, justified in doing A. And doing what is permitted is the same as being justified (in a weaker way). How to introduce a distinction? Is the distinction between having a constant and a justificational variable the most appropriate way in the context of the logic of justification? It is an open problem, but that could bring a series of ideas that could print an asymmetry between permissions and obligations, advocated as important for normative reasoning by some logicians (Makinson and Van der Torre 2003).

\subsection{Normative Intuitions in the Semantic of Artemov's systems}

Things start to get curious when we realize that not only does the axiomatic part of the logic of justification have this immediate theoretical interest for ethics. In fact, the justificational semantics must make connections with ethics too, for what we are doing here is applying logic to philosophy. It would be strange to think of Kripke's semantics for modal logic without visualizing the good applications for the notion of proper names in the philosophy of language. The formal interest behind the interpretative structures of a given language is not denied here. The semantics presented for the Logics of justifications have all the elements to be ethically relevant.

The seriality imposed for $R_{J}$ in the JD45 models may represent the externality of moral standards (perhaps facts) that justify actions in the present world (or situation), in symmetry with the seriality for $R_{r}$. If the logic for ethics is JD45, it does not matter what happens in the present world, whether people are immoral or if they do bad deeds, because the standard for the ethical justification of our actions is always present in the worlds that are referenced by the set $R_{f}$.

We have been led to the path in which systems that admit the axiom of facticity, the reflexivity of $R_{J}$ in their models, express, to some extent, a realistic ethical philosophy about moral facts. In other words, the reflexivity of systems with the axiom of factivity (e.g., J4, JT45) indicates that the actual world can be the standard to be observed to identify the justification of our actions. This view is not free of controversy, because we have allowed the reading of $t$ : $A$ as " $t$ is a (ethical) justification for the (action) A". Reflexive models admit that if in the world $w, A$ is an action with justification $t$, then the action $A$ is true. The problem is that this is not the exact characteristic of moral realism. It is not the actual action that is implied by the existence of a moral justification in the present world, but the existence of an ideal moral fact. The existence of the justification $t$ for $A$ cannot imply the realization of $A$. We have the conception of immoral act for realism: it is precisely to act against the moral fact. 
The problem above does not put us far from the elucidation that the logic of justification gives to ethics (in general). Without observing the quality of the present world, the condition of reflexivity for relation of accessibility $R_{p}$, semantic qualities of the logic of justification, and without understanding the axiom of factivity, we would not have clarified the important dimension of metaethics. The problem of adaptation, far from eliminating the application of the logic of justification in ethics, affirms the relevance for ethical analysis. We have said: the justificational reading of the ethical and metaethical theories alone represents an analytical gain. When we enter into the logic of the concept, the gain is more significant, even when the adaptation is not perfect ${ }^{19}$.

Another important semantic tool of the logic of justification is the admissible evidence function, formally described as

\section{$\varepsilon: t \times F O R \mapsto P(W)$}

This is the element that distinguishes the semantics of a justificational term $t$ from a simple operator $\mathrm{K}$ of a common epistemic logic. It is not enough, in the logic of justification, that something is true in accessible worlds. Those worlds must accept $t$ as evidence as well. This is how justification gains real force in the logic of justification. Someone fond of the traditional epistemic logic could question that the notion of truth is more than a sufficient feature of knowledge. If one knows the truth of propositions, it does not matter that we do not properly have a justification. From the ethical point of view, just like the $O$ operator in $S D L$, the possible worlds can be read as patterns of perfection that the present world observes (using $R_{j}$ ), though that alone is not enough. An ethical justification $t$ for the action $A$ requires that $A$ be the case in all accessible worlds and, at the same time, that $t$ is an admissible evidence for that $A$ in every case. We have been using "evidence" to avoid terminological confusion with Artemov's work. When we speak of the admissible reason to do something, we are talking about something closer to ethics, of a qualified obligation. Let us then adopt the nomenclature Admissible Reason Function, since we are focused on normative aspects of justifications.

Thinking about the intuition behind the semantics of the logic of justification with this ethical reading, it seems natural to believe that the simple realization of $A$ action in all accessible worlds is not enough to make us conclude that the action $A$ is justified. After all, we do not know the circumstances. The action of killing in a certain context may be inevitable for several reasons (and may always be the case, in every possible situation). Even so, the real ethical content of an action is revealed only when we confront the reason for the action in all these situations and conclude that it is admissible to act in that way. Self defense, for instance, is an admissible reason for the act of killing in several imaginable situations.

19 This work focuses on showing the many faces that the logics of justification can have and not on being a defense of any particular ethical theory. 
Some conditions in the logic of justification connect the possible worlds with the admissible reason function, as in the case of strong evidence ${ }^{20}$ and stability ${ }^{21}$, model constrains for the completeness of systems containing at least J45. In the case of strong evidence, which demonstrably implies the stability (Artemov 2008, 495), it is possible to guarantee that in all accessible situations we will have a $t$, then $t$ is an effective admissible reason in all situations as long as it is also an admissible reason in the actual situation. This shows a certain "harmony" between $R_{J}$ and $\mathcal{E}$ which suggests a naturalistic interpretation: the present situation tells us (and perhaps determines) the admissible reasons of the worlds that are our moral standards.

All the interpretation presented has some degree of indeterminacy. Moreover, we must not forget that the logics of justification, formally speaking, never had the intent to serve ethics and was presented here as an alternative to deontic logic with no real logical adaptation. All we have done was to take advantage of the power of justifications when applied to actions. Nonetheless, we can quickly note that metaethics is not fully considered, and that is a problem. Of course we have the ? and !, but these operators were not enough to cover the hard metaethics questions. The reasonable step now is to try to expand the language of the logics of justification and test for an effective gain.

\section{The Logics of Normative Justification}

Assuming that contemporaneous normative ethics consist simply in saying what is or is not obligatory or permitted to do, we could say that only the normative interpretation of the logics of justification has the potential to be sufficient for some ethical reasoning. Now, if we accept that the role of ethics involves this universality of ethical thinking, including metaethics, and the ultimate purpose of this work is holistic in the role of putting ethics in a formal way that can be fruitful, then something is missing. In order to improve our idea of normative logic, we will make two simple combinations: SDL with JD45 and SDL with JT45. That is, the application of the rules and axioms of the chosen systems without connection axioms between theories.

Technically, JT45 is a stronger system than JD45. This is easily verified, since JT45 has as one of its theorems the characteristic axiom of JD45. This means that if all we were looking for was a notion of derivability, the combination of SDL and JT45 alone would be sufficient for our purpose. It happens that the consistency axiom of the logic of justification has double interest from the normative point of view. First, the $\neg t: \perp$ form has a configuration similar to a deontic consistency axiomatization $(\neg O \perp)$, which is the option of presenting SDL made by Lennart Åqvist (1987). This may not say much if we observe only the symbolic part. In fact, the symbol is totally contingent in isolation, but together with the normative interpretation we gave, the JD45 consistency axiom is almost an informal translation of the deontic consistency. Added to this, semantically, the condition of $R_{J}$ for satisfying the consistency axiom is seriality, which is the same condition for axiom D of SDL, which carries important normative intuitions, as we already mentioned.

20 For all $w$ such that $w \in \mathcal{E}(j, A)$, then $w \vDash j: A$.

21 If $w \mathrm{R} w^{\prime}$, then $w \in \mathcal{E}(j, A)$ iff $w^{\prime} \in \mathcal{E}(j, A)$. 
JT45 is harder to apply at the same time that it fits well with the general purpose of the combination that gives life to the Logics of Normative Justification. Without the axiom of factivity, it does not seem possible to do any formalization that can translate realistic moral theories, the one that has commitments to moral facts.

Now, what are the reasons to follow the path of logical combinations? At all times, philosophy demands a complexity of resources that can make a given logic easily obsolete, useless for further meditations. Logic is, by nature, a reducer of complexities when compared to discourse in natural language. It is enough to note that propositional logic eliminates in advance any pragmatic discussion of the logical game and leaves everything on behalf of truth. This, of course, is not to say that logic cannot be useful to understand non-logical problems. The truth itself, for some purposes, like mathematics, is sufficient, what makes us understand the appreciation of mathematicians for classical logic. Philosophy, however, demands much more. Ethics require a series of elements that are not restricted to the obligations and permissions of actions. It is something complex, with passage through other great fields of philosophy, such as metaphysics and epistemology. This case, and many others, support the thesis of philosophers, such as CostaLeite, that we can only address major philosophical questions in the use of appropriate logical combinations (Costa-Leite 2003, 20).

Formally, our combinations will follow (Gabbay et al. 2003). The most basic method of combination is fusion $(\otimes)$ and is better suited for the first approach for any formal combinations. There is one advantage in which we are most interested at the present moment: fusion preserves the metalogical properties of the fused logics. Thus, due to the previous proofs of (Gabbay et al. 2003), it is not necessary to worry about the existence of a model that interprets language, consistency, soundness or completeness ${ }^{22}$. It is only necessary to make sure that our "pieces", the logics to be combined, also have the properties that we intend to maintain.

Basically, the combination procedure occurs on three levels: in language, axiomatic and semantic. Consider, for the brief structuring of the fusion, $\mathcal{L}_{S D L}, \mathcal{L}_{J D 45}$ and $\mathcal{L}_{J T 45}$ as the languages of their respective logics subscribed. For a fusion, the proposal starts, as said, by the union of the languages $\mathcal{L}$ :

$$
\mathcal{L}_{S D L} \otimes \mathcal{L}_{J D 45} \quad \mathcal{L}_{S D L} \otimes \mathcal{L}_{J T 45}
$$

In the respective axiomatizations the fusion is also made in a similar way:

$$
\mathcal{A}_{S D L} \otimes \mathcal{A}_{J D 45} \quad \mathcal{A}_{S D L} \otimes \mathcal{A}_{J T 45}
$$

In the part where language and axioms coincide, the fusion handles this in a natural way. By definition, a union is the smallest set containing the sets unified (Gabbay et al. 2003). Therefore, there is no redundancy throughout the process. Independence also remains as in the original logics: no new axioms emerge. Still in the syntactical level, it is necessary to remember that in

22 Originally, in fact, the definitive demonstration was made by Kracht and Wolter (1991). 
the presentation of the deontic logic and the logics of justification, we use formula schemes at all times. Once the language is expanded, the schemes are expanded too.

The semantic for the Logics of Normative Justification, in this context, is given by the union of the individual structures $\mathcal{D}$ :

$$
\mathcal{D}_{S D L} \otimes \mathcal{D}_{J D 45} \quad \mathcal{D}_{S D L} \otimes \mathcal{D}_{J T 45}
$$

That results in the following combinated structure:

$$
\left\langle W, R_{d}, R_{j}, \mathcal{E}\right\rangle
$$

This is a new structure with a set of "shared" possible worlds (or situations). In the case of $\mathcal{D}_{J D 45}$ and $\mathcal{D}_{J T 45}$, they share the accessibility relation $R_{j}$ and the admissible evidence function $\mathcal{E}$, although each one has different constraints. We have seen that the JT45 model has $R_{j}$ reflexive, which, inter alia, implies the seriality of the JD45 models.

Intuitively, the logic resulting from the fusion has a classical propositional basis, adding the deontic operator $O$ and the justificational terms; still in the syntactic level, fusion is the union of the deontic axioms and all the axioms that characterize JD45 and JT45. The result is a pair of logics that we have been calling indistinctly Logics of Normative Justification. Indistinctly, because they are different only in one syntactic point and one little detail in the semantic. In all deductions we are going to see, the ones arising from the fusion of SDL with JT45, and that one using the weaker version of the justification, JD45, is easily identifiable. The only difference will be the use of the axiom of factivity. As already pointed out, we are keeping JD45 for the consistency axiom and also for the class of models that satisfy the system, with serial $R_{d}$, that traditionally are connected to the normative environment.

For the sake of simplicity, let us begin with some syntactic results, by analyzing some interesting theorems of these new logics.

During a deduction with normative justifications, we can follow two basic directions: internalization of the deontic axioms and deontic necessitation of the justificational axioms.

On the side of the internalization of deontic axioms, several interesting deductions stand out. Let us take a look at some of them that immediately show Logics of Normative Justification philosophical potential, like the one below:
1. $O A \rightarrow P A$
Deontic Consistency
2. $j^{*}:(O A \rightarrow A)$
3. $j^{*}:(O A \rightarrow P A) \rightarrow\left(t^{\prime}: O A \rightarrow\left(j^{*} \cdot t^{\prime}\right): P A\right)$
4. $t^{\prime}: O A \rightarrow\left(j^{*} \cdot t^{\prime}\right): P A$ 
Something very similar happens here to our simple normative version of the logics of justification, but now the scope of justification is a modalized action. If a theory or code justifies (or validates) the obligation of action $\mathrm{A}$, then the permission is justified by the application of two justificational terms: justification of obligation and other justification arising from implication. Note that the point would be interesting for the use of normative justification, if we had a given $O A$ in some particular normative context. Using IR and line 4, we would have the detachment of $\left(\left(j^{*} . t^{\prime}\right): P A\right)$. The term $\left(j^{*} \cdot t^{\prime}\right)$ seems to indicate a stronger justification for the permission, the one that derives from the obligation, than a "pure" permission. This makes perfect sense when we think of concrete cases.

Imagine a father telling his son to eat his dinner at the table. On the assumption that everyone should obey their parents, the child would be obliged to sit at the table and eat. Imagine that the previous week, the father had given his son permission to play two hours of video games a day, and on that specific day he had not played anything. Knowing it was liver with onions day, should the son go play video-game using his original permission or obey his father's order to eat dinner immediately? See that from the point of view of the logical conflict between "obligations x permissions" and "permissions x permissions" it would hardly be solved. After all, there is a position of choice here and the common logic does not give a hierarchy of the order, or how each can overrule the other. In the Logics of Normative Justification, however, there is a way. An original position such as "Permitted to play video game two hours a day" would be an axiom in the normative system of this home, which could be internalized with a constant justification. The permission that results from the obligation carries the constant applied with another term. In a sense, therefore, it has a more complex justification, of the type $\left(j^{*} \cdot t^{\prime}\right)$. The determination that the justification of the more complex permission overlaps that of the least complex is not clear in The Logics of Normative Justification. It is not the case that $\left(\left(j^{*} \cdot t^{\prime}\right): P A\right)$ implies in $\left(j^{*}: P A\right)$. The derivability is not an argument for the asymmetry that it is intended to impose. The weight of the justifications is due to the complexity of the justification term. The kid would have to sit at the table and eat.

The example of the child who does not want to eat may seem trivial, at the same time it reveals an intricate concept within normative logics, which is to distinguish the various types of permission, something impossible to do with SDL. David Makinson and Van der Torre (2003) consider this problem as a result of the simplicity of deontic logic. They argue that an operator (in this case, "permitted that..."), present in SDL, is unable to normatively represent the differences between the types of permission. How, within a context, can we distinguish an explicit permission (the authors call it positive) from derived permission (e.g., which is consequent of a conditional obligation)? How can these be distinguished from permissions resulting from an absence of prohibition (negative permission)? The Logics of Normative Justification have the resources to show us, without major complications, the asymmetries necessary to define permissions more complex than the simple $P$ operator. 
Let us see another theorem:

1. $O(A \rightarrow B) \rightarrow(O A \rightarrow O B)$

(K-deontic)

2. $\quad j^{*}:(O(A \rightarrow B) \rightarrow(O A \rightarrow O B))$

3. $t^{\prime}: O(A \rightarrow B) \rightarrow\left(j^{*} \cdot t^{\prime}\right):(O A \rightarrow O B)$

4. $\quad\left(j^{*} \cdot t^{\prime}\right):(O A \rightarrow O B) \rightarrow\left(t^{\prime \prime}: O A \rightarrow\left(j^{*} \cdot t^{\prime}\right) \cdot t^{\prime \prime}: O B\right)$

5. $\quad t^{\prime}: O(A \rightarrow B) \rightarrow\left(t^{\prime \prime}: O A \rightarrow\left(j^{*} \cdot t^{\prime}\right) \cdot t^{\prime \prime}: O B\right)$

This is an interesting result, since the previous problem also suggests that the conditional obligation in deontic logic is the source of many challenges. The consequent obligation in line 5 carries three different justifications, which raises philosophical ideas on the factual and modal detachment in normative logics. What could this product of justifications mean under an obligation? How can the combination be different from the sum of justifications? Our suggestion is that it is an increase in the complexity of the justifications of the obligation, which makes them stronger from an ethical-argumentative point of view. Does this make sense for the above theorem? It is necessary to think for a while. The antecedent obligation has only the term $t$ as justification, but it does not apply to the action itself. It does not try to compel an action, even if instead of $A$ and $B$ schemes we had atomic, singular actions. The same comment goes for the $t^{\prime \prime}$ : $O A$. In the action plan, what matters is $O B$. To get $O B$ alone, we would need two modus ponens, two background checks, which result in a "superjustification" $\left(\left(j^{*} \cdot t^{\prime}\right) \cdot t^{\prime \prime}\right)$. These new complex terms appear to be important in order to make distinctions within ethical theories, such as the Kantian one. The categorical imperative has no hypothesis. It is a "pure" obligation. The hypothetical imperative, as the name already says, has a condition, therefore, it is not universal. How would we know what this condition is? Normative Justification makes it very clear in the syntactical level!

The other side of the deductions of the combined logics is the "deontologization" of justifications. Let us see one of these cases:

1. $\quad t:(A \rightarrow B) \rightarrow\left(t^{\prime}: A \rightarrow\left(t . t^{\prime}\right): B\right)$

2. $O\left(t:(A \rightarrow B) \rightarrow\left(t^{\prime}: A \rightarrow\left(t . t^{\prime}\right): B\right)\right)$

1 NEC-O

3. $O(t:(A \rightarrow B)) \rightarrow\left(O\left(t^{\prime}: A\right) \rightarrow O\left(t . t^{\prime}\right): B\right)$

$\mathrm{K}+\mathrm{MP}$

This theorem reveals itself as a new form of application, now with deontic operators. This theorem raises a question: is the different scope of $O t: A$ and $t: O A$ important? The intended reading of the formulas is what will decide the matter. Is " $t$ is a justification for the obligation of action A" different from saying "obligatory that $t$ is a justification for action $A$ "? The former seems to act at a higher level of normativity, as to the validity or relevance of obligations, while the second imposes justification as an argument that directly accompanies action. If this is not clear 
enough, an example can help. We know that killing is wrong, on the legal and moral level. The justifications for prohibition (obligatory not to do...) are diverse: impossibility of universalization (Kant), does not bring happiness (utilitarianism), is approved by society (legal justification) and so on. These are cases that appear as an "external" justification of the obligation. We also know that there are contexts that killing is a justified, fully moral action. The case of a father who kills to defend his child is remarkable. It is not the case that he is now with a justification of the same level to kill someone, but his obligation to protect his son or daughter imposes a moral justification for his action. Nobody can be morally accused for doing what the obligation dictates, as long as the obligation presents the context $t$ that justifies the acts in question.

The problem is that the derivation within the Logics of Normative Justification may very well take the conflicting paths and confuse these two readings intended. A derived rule, however, seems to put us "back on track":

\section{If $A$ is axiom, then $O j^{*}: A$.}

It is obvious that this rule is valid, since for any axiom the internalization rule (IR) is valid, and as far as it is deductible $(\vdash)$, the deontic necessitation rule can be applied. The internalization of obligatory formulas cannot be generalized, since it only applies to the axioms of SDL. There is a limit, given by CS and by the axiomatic, on what can be internalized or not.

The next theorem, in the same way, reveals itself as the monotonicity in its deontic version:

1. $\quad t: A \rightarrow\left(t+t^{\prime}\right): A$

MON

2. $O\left(t: A \rightarrow\left(t+t^{\prime}\right): A\right)$

1 NEC-O

3. Ot: $A \rightarrow O\left(t+t^{\prime}\right): B$

$\mathrm{K}+\mathrm{MP}$

This is another theorem that in the field of ethics seems to be always plausible. An intuitive reading may reinforce: "if it is obligatory that $t$ is a justification for doing A (ethically), then it is obligatory that $\left(t+t^{\prime}\right)$ is also a justification for doing A (ethically)'. The father who saves the child in danger and kills the aggressor not only fulfills an obligation, but gains the justification $t$ that context imposes. If in addition to threatening the life of his son, the aggressor still threatens the life of the father, the action of killing still remains obligatorily justified.

At this point we must remember that $t$ does a refined kind of iteration of operators, different from the one made in the usual modal logic. For justification, introspection is similar to a "referee report certifying that a paper is correct, a computer verification output given a formal proof of an input, a formal proof that is proof of $F$, and so forth." (Artemov 2008). A moral justification can also be verified: approval of action or justification of action by a person, political or social outcomes may represent a verification of the "quality" of justification in place. Kant, for instance, built all his ethics on a very particular quality of obligations (or imperatives): on the possibility of universalization of the principle of the action (Hare 1996). Could this principle be reduced to 
justification and the possibility of universalizing a moral proof?

Perhaps the presentation of negative introspection leaves the role of normative verification more understandable:

1. $\neg t: A \rightarrow ? t:(\neg t: A)$

2. $O(\neg t: A \rightarrow ? t:(\neg t: A))$

NEC-O

3. $O \neg t: A \rightarrow O(? t:(\neg t: A))$

$\mathrm{K}+\mathrm{MP}$

If it is necessary to verify the relevance of a justification for obligations, then it is necessary to verify the impertinence of a justification of an obligation, when $t$ is not a justification. Ethically, the agent not being justified for an obligatory or permitted action, it is possible, according to the result, to be confirmed by some means: disapproval of that justification by a group of people, pragmatic results such as unhappiness, any fact that removes that justification from the modalized action.

Let us try to make this simpler by using a moral example. For an alcoholic, drinking (d) causes happiness $(\mathrm{t})$. Although controversial to the most conservative fellow, it is not denied that alcohol alters the mood of many. It is permitted (legally, by society), prima facie, to drink $(P d)$. We can therefore say, within a logic of normative justification, that

$$
t: P d
$$

it is the case for the alcoholic. The hedonistic theory confirms that if $t$ brings happiness, $t$ is a moral justification for the alcoholic to do what he is permitted to do - in other words, the hedonistic theory "justifies the justification" positively (!). Suppose now that the alcoholic thinks about doing something else that he is allowed to do: go to a rehabilitation clinic $(P c)$. If he really loves drinking, we can assume that going to rehab causes suffering, because there are no alcoholic drinks there $\left(t^{\prime}\right)$. So we have

$$
\neg t^{\prime}: P C
$$

From the hedonistic perspective, again, if not drinking causes the alcoholic suffering, we can verify that $t^{\prime}$ is not a justification for $P C$.

\subsection{Semantics for the Logics of Normative Justification}

Since the method for combining logics we have used is that of (Gabbay et al. 2003), the resulting structure for the Logics of Normative Justification is immediate:

$$
\begin{aligned}
& \mathcal{D}=\left\langle W, R_{d^{\prime}} R_{,}, E\right\rangle \text { s.t. } \\
& W \neq \emptyset
\end{aligned}
$$




$$
\begin{aligned}
& R_{j} \subseteq W \times W ; \\
& R_{d} \subseteq W \times W ; \text { and } \\
& \varepsilon: t \times F O R \mapsto P(W) .
\end{aligned}
$$

Intuitively, $W$ is a non-empty set of possible worlds, $R_{j}$ is the justificational accessibility relation, and $R_{d}$ is the deontic accessibility relation. $\mathcal{E}$, element added to the usual structure for modal logics, it is worthwhile remembering, is the admissible reason function, which designates a set of possible worlds in which $t$ is an admissible reason for action $A$. All relations and the function of admissible justification are subject to constraints in order to satisfy the axioms of both Logics of Normative Justification:

- $R_{j}$ is euclidian ${ }^{23}$; reflexive and monotonic in its relation to $\mathcal{E}^{24}$.

- $R_{d}$ is serial ${ }^{25}$.

- $\mathcal{E}$ respects:

Application: $\mathcal{E}(j, A \rightarrow B) \cap \mathcal{E}\left(j^{\prime}, A\right) \subseteq \mathcal{E}\left(j \cdot j^{\prime}, B\right)$; and

Sum: $\varepsilon(j, A) \cup \mathcal{E}\left(j^{\prime}, A\right) \subseteq \varepsilon\left(j+j^{\prime}, B\right)$.

In addition, $\varepsilon$ is closed by

Positive introspection: $\mathcal{E}(j, A) \subseteq \varepsilon(! j, j: A)$;

Negative Introspection: $\varepsilon(j, A)^{c} \subseteq \varepsilon(? j, \neg j: A)$;

Strong Evidence: for every $w$ such that $w \in \mathcal{E}(j, A$, ), then $w \vDash j$ : $A$;

Stability: if $w R w^{\prime}$, then $w \in \mathcal{E}\left(j, A\right.$, iff $w^{\prime} \in \mathcal{E}(j, A,)^{26}$.

Note that $\mathcal{D}$ respects CS, since for every $w$ there is a $j^{*}$, if $w \in W$, then $w \in \mathcal{E}\left(j^{*}, A\right.$, ) for any $j^{*}$ : $A$. In this case, since the justificational systems chosen in the combinations are JD45 and JT45, CS is axiomatically appropriated, therefore IR is guaranteed.

Now we can present a model which is easy to present: $\mathcal{M}=\langle D, \vartheta\rangle$. Considering the model, we can define the satisfaction conditions for the Logics of Normative Justification:

$\vartheta(p, w)=T$ ou $\vartheta(p, w)=F$, for $p$-atomic;

$w \vDash p$ iff $\vartheta(p, w)=T$ s.t. $w \in W, p$-atomic;

23 For all $w$, w' and $w^{\prime \prime}$ if $w R w^{\prime}$ and $w R w^{\prime \prime}$, then $w^{\prime} R w^{\prime \prime}$.

24 If $w R w^{\prime}$ and $w \in \mathcal{E}(t, A)$, then $w^{\prime} \in \mathcal{E}(t, A)$.

25 For every $w$ there is a $W^{\prime}$ such that $w R w^{\prime}$.

26 Monotonicity of $\mathrm{R}_{\mathrm{j}}$. 


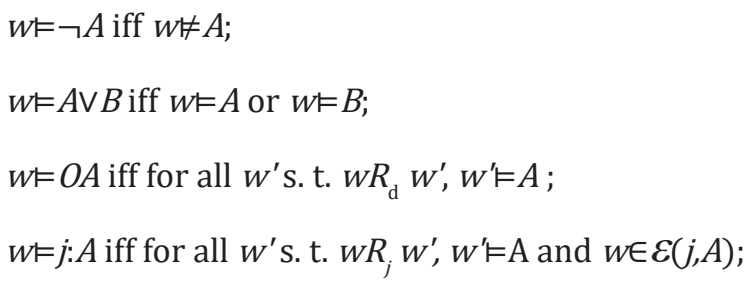

Theorem. The Logics of Normative Justification are sound and complete for the class of all Kripke's models that have $R_{\mathrm{d}}$ serial $R_{\mathrm{j}}$ euclidean, reflexive and monotonic in relation to $\varepsilon$; $\varepsilon$ is closed by negative introspection and strong evidence.

The proof presented in (Gabbay et al. 2003) and (Kracht and Wolter, 1991) guarantees this result and gives the Logics of Normative Justification the basic properties that any logic must have.

\subsection{Applications}

\subsubsection{Ross's paradox}

A prime example of the power of this emancipation from the pure deontic logic is the paradox of Ross (1944). The paradox is simple and controversial as a genuine paradox (and perhaps that is why we must be careful about it). We must go straight to formalization, because the notion of classical deduction in deontic logic is the center of the problem. Considering only SDL for formalization, suppose the following case: a boss, wishing to send a letter, delivered the envelope to an employee saying: "It is obligatory to post this letter (p)". In SDL, the formalization of the command can only be put as $O p$. In the use of the classical axiom $A \rightarrow(A \vee B)$, we can derive $O(p \rightarrow(p \vee Q))$, and by NEC-O and MP derives

$$
O(p \vee q)
$$

for any $q$. The whole sentence is usually read as "obligatory to post the letter or burn it". Burning the letter, an example of any $q$, does not represent an action capable of fulfilling the order that originally demanded to post it. On the contrary, it is a situation that completely prevents the fulfillment of the original order.

As mentioned, many still question the paradoxical aspect of Ross's objection. Georg von Wright had always rejected that the derivability of an obligatory disjunctive formula is in fact the proof that a normative (empirical) system proves a disjunctive and counterintuitive obligation. The definition of what is or is not a paradox is a decision of philosophy of logic and will invariably depend on the concept of paradox. However, it is undeniable that on a simple modal basis, such as $S D L$, it is impossible to formally define the status of formulas of the type $O(A \vee B)$, center of what is called Ross's paradox. In the Logics of Normative Justification, however, the power of analysis are significantly higher. Let us formalize Ross's context with (normative) justicational terms: 

1. $A \rightarrow(A \vee B)$
PC
2. $j^{*}:(A \rightarrow(\mathrm{A} \vee B))$
1 IR
3. $\mathrm{t}^{\prime}: A \rightarrow\left(j^{*} \cdot t^{\prime}\right):(A \vee B)$
$\mathrm{AA}+\mathrm{MP}$
4. $O\left(t^{\prime}: A \rightarrow\left(j^{*} \cdot t^{\prime}\right):(A \vee B)\right)$
3 NEC-O
5. $\left.O t^{\prime}: A \rightarrow O\left(j^{*} \cdot t^{\prime}\right):(A \vee B)\right)$
$\mathrm{K}+\mathrm{MP}$

In the original paradox, we have $O P$ for the obligation to send a letter. In the context of normative justifications, once an order is given, in addition to natural obligation, the action is also justified, from the point of view of the employee who was assigned to the task. The formalization, therefore, would be $O t: p$ in which $p$ is the action of sending the letter. Using the result above, we can represent the following formula:

$$
O\left(j^{*} \cdot t^{\prime}\right):(p \vee q)
$$

In which q represents the action of burning the letter. The paradoxical obligation, therefore, starts to show an applied justification, in which one of them is a constant. In this sense, we can follow the Georg von Wright and argue that there is a difference between proving a mandatory formula and proving the existence of a genuine obligation for a normative system. Although the role of justification constants is not fully understood yet, especially if we compare with Artemov's logic of probability, it is enough to show a strong philosophical application that Normative Justification can syntactically print. Only SDL does not have this expressive power.

Note, as an alternative formalization, that we could keep $O p$ as an "extra" axiom of an internal company code that you want to send the letter. A reliable normative logic, it is good to say, has to be able to deal with these more practical codes as well. Not everything in the normative world is right (strictly speaking) or universal ethics. Then, considering $O p$ an axiom of the internal code, it follows that $j^{*}: O p$ is theorem, by IR. Considering that $O t^{\prime}: A \rightarrow O\left(j^{*} \cdot t^{\prime}\right):(A \vee B)$ is the result of the justified obligation of the classical axiom $A \rightarrow(A \vee B)$, the paradox completely changes its configuration. In particular, we cannot make the detachment of the disjunctive obligation which is the origin of Ross's paradox. It is a genuine blockage of the paradox, from the syntactic and philosophical point of view.

\subsubsection{Prima facie and all-things-considered obligations}

A very common problem posed in the usual deontic logic is to formalize the differences between prima facie and all-things-considered obligations (Rönnedal 2010, 37). Generally speaking, a prima facie obligation has a characteristic, which

is the reason to do the action in a given situation if and only if, in any case where that situation occurs and has no opposite reason, the placement of that situation makes it mandatory to do the action A. (Copp 2006, 134) 
If the word "reason/motive" is replaced by justification, and it can be done without any complication, as we have done with metaethical theories, then it is possible that we make use of the logic of normative justification to deal with the problem.

So, we have a $(t: A)$. According to the definition of prima facie obligations, if the system does not contain $t: \neg A$, then $O A$. Note, in advance, that the justification for abstaining from $A$ is different from the justification for doing $A^{27}$ :

$$
(t: A) \wedge \neg\left(t^{\prime}: \neg A\right) \rightarrow O A
$$

These are the prima facie obligations in the Logics of Normative Justification. An All-thingsconsidered obligation can be defined as an obligation that even in the presence of a conflicting justification for $A$, still holds $A$ as obligatory. Formalizing:

$$
(t: A) \wedge\left(t^{\prime}: \neg A\right) \rightarrow O A
$$

The problem is relevant when we want to define attitudes to be taken in the presence of conflicting rules. This is the case of what is known as Sartre's dilemma. The man who commits himself to go to war to defend his country, therefore forced to do so, finds himself in conflict when, due to his obligation to take care of his parents, he realized that his mother is sick. Should the man go to war or take care of his mother? If every obligatory action has the same status, deontic logic alone can do nothing to solve this dilemma. With the formal definition of justification, however, and defining the action of caring for the mother as an all-things-considered obligation, even in the presence of an opposite justification to help the mother, e.g., to defend his country in a war, the obligation to help the mother remains. This mechanism is represented by the above formulas, since the derogatory effect (of canceling the competing obligation) is given by the connected justificational term. In this case, it is interesting to note how the justification of $A$ translates into the striking feature that makes $A$ ethically correct. This brings us very close to the moral naturalism. Would that be the case? Seems like it, but we do not need to decide now. All we want here is to show the power of Logics of Normative Justification. And we have done so, since it is easy to see that without justification the distinction between obligations would not be possible.

\subsubsection{Relativism and triviality}

The Logics of Normative Justification provide the tools to make a curious parallel between moral relativism and triviality. Although the comparison, in some extent, is easy to understand, as far as this research went, no mention was ever made of coincident behavior of triviality and relativism. It is not known whether it is because logicians know the problems of trivialization, but do not know metaethics, or, conversely, that metaethics scholars do not know much logic. The fact is that this relation can be given in the proper ethical and logical manner, as we can show using the Logics of Normative Justification.

27 Is this always the case? If we are classical, the answer may be yes. In order to have a definitive position about it we would need new developments. Primarily, it would be required a logic with extra axioms besides those from the combination. This will be the object of future work. 
Imagine that a philosopher has developed a new ethical theory, based on an action's criteria that he considered special. After publishing his book, another scholar realizes that the same ethical criterion could be applied to a number of actions not initially foreseen, including some that were contrary to what the original theory considered moral in a given context. What follows? The first published theory implies relativism. In ethics, if a theory is relativistic or implies some form of relativism, one loses the ability to "judge" actions, to distinguish good from bad, right from wrong, prohibited from the obligatory. One could not therefore conceive that the theory that classified $A$ as ethically correct, consider $\neg A$ correct as well. The formalization with normative justification implies that a theory that justifies $A$ and $\neg A$, at the same time and based on the same criteria, could not be taken seriously.

This situation is very much like the "adventure" of developing a new logic. If our base is classical, in our addition of non-logical axioms we must be careful not to prove $A$ and $\neg A$. Once a contradiction has been proved, for ex falso quodlibet any formula B can be derived. The logic becomes trivial. Everything, from the point of view of probability, becomes theorem in a contradictory theory and, thus, one loses the formal instrument of judging what truth is or is not. Just as the ethical system becomes useless with derived relativism, logic becomes useless in the presence of a contradiction.

The difference between relativism and trivialization, however, is the determination of concepts. We know the devastating effect of trivialization, since what is a contradiction is something well defined, the use of the principle of ex falso quodlibet is well defined and, finally, the concept of demonstration is well defined. Thus, the approximations between relativism and triviality are only consequential and informal. There was, as we have said, no formal representation of metathetics that is able to demonstrate that being relativistic is the same as being trivial. At this point, our statements are just conjectures.

As stated, the logic part is well defined: any logician knows the effects of trivialization. The same is not the case with relativism. Justification, however, gives us a clue. What does a theory say that an action $A$ is correct, good? For the Logics of Normative Justification, it means that $A$ has a justification $t$ (in that theory). In this case, we have

\section{t:A}

If the theory has been relativized, this same justification $t$ works for the denial of $A$ (since it serves any action), then we also have

$$
t: \neg A
$$


The formula $t: A \rightarrow \neg t: \neg A$ is a theorem easy to prove in the Logics of Normative Justification ${ }^{28}$. Since we already have $t: A$ and both Logics of Normative Justifications are closed by $M P$, then $\neg t: \neg A$ is the case. We have a contradiction. Relativism in fact trivializes moral systems with normative justifications. Since its basis is classical, like any proper extension of the logics of justification, ex contraditione quodlibet applies without restrictions. Thus, any action $B$ can be proved and, in particular, can have the form $t: B$.

We have to take a moment to analyze two questions to get rid of any future problems: first, if our formalization of the way relativized theories justify actions actually works; second, if $(t: A \rightarrow \neg t: \neg A)$ must be a theorem, since it seems too strong for the moral realm.

The first question apparently does not need further explanation. If relativism means that every action has a justification, when a theory is relativized, we can say that it justifies any action. In particular, it justifies $A$ and $\neg A$. The second question, however, we have to open up a little more the concepts involved in the problem and see if we could still save relativism from criticisms of trivialization of moral theories.

In a recent article, Costa-Leite (2018) developed an argument that can save relativism from the identification with trivialization. In a relation with the works in Newton da Costa's justification logic (da Costa 1997), at some point becomes clear that the definition of strong justification coincides with the central theorem $t: A \rightarrow \neg t: \neg A$, which makes the relativism a metaethical version of trivialization. In fact, with some notational difference, this theorem corresponds to the characteristic axiom of Newton da Costa's justification system. What Alexandre Costa-Leite calls the problem of the partial justifications (PJP) has everything to do with our problem. Says the author: how is it possible that contradictory propositions are simultaneously justified without destroying the system of inferences? Reformulating: how can an ethical theory justify contradictory actions without trivializing the system? Or, how to eliminate the identity between relativism and trivialization? Let us call this context Problem of Partial Normative Justification.

The resolution goes through what the author calls "modification of the referential system", so that we could be able to see that all justification can be seen as partial justification (Costa-Leite 2018 , 98). This implies switching from the classical basis for a weaker one, in particular those that blocks the derivation $(t: A \rightarrow \neg t: \neg A)$. The author uses trivalent logic, presenting other formal options and alerting on the various ways of following this weak approach to justification.

The key point would be to show that ex false quodlibet is not valid, and we do not have $t: B$

28 The proof takes just a few steps:

1. $t: \neg A \rightarrow \neg A$

FAC

2. $\neg \neg A \rightarrow \neg t: \neg A$

PC

3. $A \rightarrow \neg t: \neg A$

PC

4. $t: A \rightarrow A$

FAC

5. $t: A \rightarrow \neg t: \neg A$

3,4 PC 
to any $B$ in relativistic contexts. This, however, would require a very drastic change in Logics of Normative Justification, which does not fit on this occasion. For now, we are pleased to demonstrate that our new logics, based on normative justification, show the real destructive side of relativism.

\section{Conclusion}

Normativity is much more than deontology and our quest into metaethics showed that ethics is much more than preaching about actions. In fact, they involve questions that surround the whole tradition and require all the tools that philosophy can provide. It is not just a matter of saying what kind of action is obligatory or good. It is necessary to be able to express some external relations, those linked to concepts that do not seem normative at first sight.

If philosophy's vocabulary is forced to its limits with the requirements of metaethics, what about the very limited resource of contemporary deontic logic, still centered on the notion of deontic operators? The preliminary investigation of some of the metaethical theories has shown an interesting fact: their most relevant propositions can be translated in terms of justification without loss of information.

When we speak of justification, it is impossible not to refer to the logic of justification, which has gained new impetus with the developments of Sergei Artemov. The concept of justification, previously only informally connected with knowledge and ignored by epistemic logicians, has proved to be a central concept for the formal development of epistemology. The suggestion for the normative field, therefore, was immediate. Why not develop a normative logic centered on the concept of justification? First of all, it was surprising to see how the simple change in the intuition of the terms and formulas of the logics of justification to an ethical bias completely changed the meaning of the axioms and proved to be fit almost perfectly into ethical discourse. Application, factivity, and monotonicity were in direct connection with normative concepts and the ethical case. We have even been able to revive the debate on axiom $\mathrm{T}$ in ethics. The axiom $\mathrm{T}$ was practically defined within the deontic logic and very little explored in the literature of formal ethics. This first level required no formal maneuver, only the logic reading changed, and some intuitions about normative and metaethical ethics emerged. Moving a higher level by combining two systems of justification with SDL, the intention was to make the logic more expressive in order to go deeper in the metaethical debate. More than that, it was possible to advance towards a logic of ethics (in general) by solving internal problems of deontic logic. Ross's paradox resolution is striking, for it would not have been enough to "solve" the paradox, since it is doubtful if it is in fact a paradox. The Logics of Normative Justification give a very simple answer to these questions and highlights what is strange about the seemingly paradoxical deduction. The problems of the prima facie and all-things-considered obligation have also a successful approach within our logics, although further testing should be made in the future.

Regarding the "faults" to be supplied in further research, there is also much to be said. At the most important point, which was the combination of logics, this work could only achieve the 
maximum potential of the use of logic in philosophy if we had gone beyond fusion as a method of combining logics. In combinations without additional axioms, we do not have any formulas that would seem perfect for us. This is the case of the following formulas:

$$
\begin{gathered}
O A \rightarrow t: A \\
P A \rightarrow t: A
\end{gathered}
$$

These two formulas, if they were added as axioms, would mean a definition of deontological concepts in the logic of justification. The challenges of introducing new axioms, such as the above, are known: we would lose indispensable metalogical results.

At other times, as in the use of normative justifications to distinguish prima-facie and allthings-considered obligations, the lack of first-order was evident. The current status of Logics of Justification is precisely towards first order. It would be interesting to be able to express ideas that "there is a justification against action A" or "all justification is in favor of doing A". Considering that our purpose was introductory, this modification will be addressed in future works.

Naturally, other problems regarding the Logics of Normative Justification will most likely emerge with further studies. Regardless of those flaws, we hope that, with this short presentation, we were able to show how some freedom in logics could give new ideas towards the development of a formal philosophical reasoning.

\section{References}

Anderson, Alan R. "Some nasty problems in the formal logic of ethics." Noûs 4 (1967): 345-360.

Åqvist, Lennart. Introduction to deontic logic and the theory of normative systems. Naples:

Bibliopolis, 1987.

Artemov, Sergei. “The logic of justification.” The Review of Symbolic Logic 4 (2008): 477-513.

Bealer, George. Quality and concept. New Haven: Yale University Press, 1982.

Blackburn, Patrick, Rijke, Martin and Venema, Yde. Modal logic. Cambridge: Cambridge University Press, 2002.

Branquinho, João, Murcho, Desidério and Gomes, Nelson G. Enciclopédia de termos lógico-filosóficos. São Paulo: Martins Fontes, 2006.

Carnielli, Walter and Pizzi, Carlos. Modalities and multimodalities. Berlin: Springer, 2008.

Carneiro, Gregory. "Lógica da Justificaçấo Normativa: Interpretaçôes e Aplicaçôes Filosóficas." Master dissertation, University of Brasília, 2019.

Chisholm, Roderick. Teoria do conhecimento. Rio de Janeiro: Zahar, 1974.

Chrisman, Matthew. What is this thing called Metaethics? London: Routledge, 2016.

Copp, David. The Oxford handbook of ethical theory. Oxford: Oxford University Press, 2006.

Costa-Leite, Alexandre. "Interactions of metaphysical and epistemic concepts." PhD dissertation, University of Neuchatel, 2007.

Costa-Leite, Alexandre. "O problema das justificaçôes parciais". Revista de Filosofia Moderna e Contemporânea 6 (2018): 95-104.

da Costa, Newton. O conhecimento científico. Curitiba: Editora discurso editorial, 1997. 
Dancy, Jonathan. "Nonnaturalism," in The Oxford handbook of ethical theory, ed. David Coop, 122-145. Oxford: Oxford University Press, 2006.

Darwall, Stephen. "Morality and practical reason: A Kantian approach," in The Oxford handbook of ethical theory, ed. David Coop, 282-320. Oxford: Oxford University Press, 2006..

Faroldi, Federico and Protopopescu, Tudor. "A hyperintensional logical framework for deontic reasons." Logic Journal of the IGPL 27 (2019): 411-433.

Gabbay, Dov, Kurucz, A., Zakharyaschev, M. and Wolter, Frank. Many-dimensional modal logics: theory and applications. Amsterdam: Elsevier, 2003.

Gettier, Edmund L. "Is justified true belief knowledge?.” Analysis 23.6 (1963): 121-123.

Hare, Richard M. A linguagem da moral. São Paulo: Martins Fontes, 1996.

Hume, David. Tratado da natureza humana. São Paulo: Unesp, 2009.

Jørgensen, Jørgen. “Imperatives and logic.” Erkenntnis 7 (1937): 288-296.

Kant, Immanuel. Fundamentação da metafísica dos costumes. Lisbon: Ediçōes 70, 1995.

Kracht, Marcus and Wolter, Frank. "Properties of independently axiomatizable bimodal logics." Journal of Symbolic Logic 56 (1991): 1469-1485.

Kuznets, Roman. "Complexity Issues in Justification Logic.” PhD dissertation, City University New York, 2008.

Makinson, David. "On a fundamental problem of deontic logic." Norms, Logics and Information Systems. New Studies on Deontic Logic and Computer Science (1999): 29-54.

Makinson, David and Torre, Leon van der. "Permission from an input/output perspective." Journal of Philosophical Logic 32 (2003): 391-416.

Mcnamara, Paul. "Deontic logic," The Stanford Encyclopedia of Philosophy, Stanford: Stanford University, 2014.

Plato. Teeteto. Lisbon: Calouste Gulbenkian, 2008.

PRIEST, Graham. In contradiction. Oxford: Oxford University Press, 2006.

Rönnedal, Daniel. An introduction to deontic logic. Stockholm: CreateSpace, 2010.

Rönnedal, Daniel. “Quantified temporal alethic-deontic logic,” Logic and Logical Philosophy 1 (2015): 19-59.

Ross, Alf. "Imperatives and logic". Philosophy of Science 1 (1944):30-46.

Sinnott-Armstrong, W. "Moral skepticism". The Stanford Encyclopedia of Philosophy. Stanford: Stanford University, 2015.

Vázquez, Adolfo S. Ética. Rio de Janeiro: Civilização Brasileira, 2013.

Wright, Georg H. "Deontic logic.” Mind 237 (1951): 1-15. 
